\title{
Dynamic Lot Optimization of Assembly Supply Chain with Delivery Time Constraint
}

\author{
Shuang-yan $\mathrm{Li}^{1}$, De-zhi Zhang ${ }^{2}$ \& Fang-ping $\mathrm{Jin}^{2}$ \\ ${ }^{1}$ College of Transportation and Logistics, Central South University of Forestry and Technology, China \\ ${ }^{2}$ School of Transportation Engineering, Central South University, China \\ Correspondence: De-zhi Zhang, School of Transportation Engineering, Central South University, 410075, China. \\ E-mail: dzzhang@csu.edu.cn
}

Received: August 5, 2013

Accepted: August 27, 2013

Online Published: October 28, 2013

doi: 10.5539/ibr.v6n11p73

URL: http://dx.doi.org/10.5539/ibr.v6n11p73

\begin{abstract}
In this paper, we investigate operational decision optimization problem of assembly manufacturing capacitated supply chain. Open equations of this system in all planning periods are set up. Delivery time to clients form a time window that limits point to assembly manufacturer delivery start and end time. The system model divide planning time into many equally periods, and decisions can vary with time. Ability constraint in the process of supply chain operation, time constraints and assembly production constrain are all considered in the inventory control dynamic batch optimization model. We solve the optimization problem by hybrid mixed integral optimization and SQP algorithm. At last, we examine a set of numerical examples that reveal the insights into the dynamic inventory control policy and the performance of such an assembly type inventory mode.
\end{abstract}

Keywords: dynamic optimization, delivery on time, SQP algorithm

\section{Introduction}

Assembly manufacturing enterprises are different from processing production enterprises, because their products are composed by a variety of component which has a strict assemble relationship, that's why no component are allowable to be missing when it comes to assemble. It is also different from daily goods production enterprise. Because backlog penalty is serious, delivery in time is the primary goal of assembly manufacturing enterprises. For customer generally requiring delivery should be finished before the deadline, delivery is a window time constraint type. So the supply chain operation optimization is to minimize the whole operation cost while fulfill orders in time. Decision optimization to meet the requirement of the assembly manufacturing enterprise supply chain is also a practice problem.

\section{Literature Review}

In assembly manufacturing supply chain optimization, the ratio of components in the assembly process according to bill of material must be considered. An assembly manufacturing supply chain includes several components. The key issue in an assembly system is the coordination of the components, while the key issue in a distribution system is the allocation of the component among the products. An ATO system combines the elements of assembly and distribution, and resolves both coordination and allocation issues. This makes the ATO systems difficult to analyze, design, and manage (Song \& Zipkin, 2003).

Dan et al. (2007) solved the problems of optimization arranging job sequences of a supplier and a manufacturer in a three-stage supply chain. A cooperative batch scheduling model with due windows was established for collaborative decision-making between the supplier and the manufacturer. The objective is to minimize the overall logistics and delivery cost, which include the costs of inventories, transportation and penalties without delivery in time across the supplier and the manufacturer.

There are many literatures about delivery constraint production and transportation planning problems. The dynamic lot-sizing can be divided into two categories as refer to uncapacitated problem (Aggarwal \& Park, 1993; Federgruen \& Tzur, 1991) and capacitated version (Anily, Tzur \& Wolsey, 2009; Van Hoesel \& Wagelmans, 1996). With system collaborative operation, the time of delivery time is a interval period rather than a point time that known as the delivery time window. (Lee, Çetinkaya \& Wagelmans, 2001) studied the dynamic lot-sizing problem with demand time windows and provides polynomial time algorithms for computing its solution. If 
shortages are not allowed, the complexity of the proposed algorithm is $\mathrm{O}$ (T2). When backlogging is allowed, the complexity of the proposed algorithm is O (T3). Jaruphongsa and Lee (2008) consider speculative costs and given a optimal algorithm based (Lee, et al., 2001). They researched lot optimization with delivery tine windows in which production are transported by container and cost of transportation is incurred. A polynomial time algorithm suggested for the problem in which every time window is not strictly covered with other time windows.

Classical dynamic lot-sizing problem by considering production capacity constraints as well as delivery and/or production time windows was summarized (Hwang, Jaruphongsa, Çetinkaya \& Lee, 2010). They used an untraditional decomposition principle. They developed a polynomial-time algorithm for computing an optimal solution for the problem under the assumption of non-speculative costs. The proposed solution methodology is based on a dynamic programming algorithm. And two new mixed integer programming models for capacitated multi-level lot-sizing problems with backlogging, whose linear programming relaxations provide good lower bounds on the optimal solution value (Wu, Shi, Geunes \& Akartunal1, 2011).

In fact, economic lot and delivery scheduling problem for a multi-stage supply chain comprising multiple items is complex. It is required to develop a synchronized replenishment strategy, and specify the sequence of production and the replenishment cycle time that achieves synchronization through the supply chain at minimum cost (Osman \& Demirli, 2012).

The problem to cooperate multiple levels decision of a supply chain is important. It is well known that coordination members of supply chain can lead to benefits for whole supply chain. And that optimising single stage alone may not be sufficient for an enterprise. So, more and more scholars has studied on cooperation of whole supply chain, rather than a single stage. Kim, T., \& Glock, C. H. studied the case of a multi-stage supply chain where equal- and unequal-sized batches are transported between the stages and where penalty costs are imposed for long lead times. Unlike earlier works, They did not restrict the number of stages to a given value, but rather analyses a general case of the model (Kim \& Glock, 2013). Glock, C. H. reviewed lot-size models which focus on coordinated inventory replenishment decisions between buyer and vendor and their impact on the performance of the supply chain. These so-called joint economic lot size (JELS) models determine order, production and shipment quantities from the perspective of the supply chain with the objective of minimizing total system costs (Glock, 2012).

\section{Optimization model with delivery time constraint}

As shown in figure 1, first stage nodes indicate suppliers who process and supply all needed components for manufacturers. Second stage node is manufacturer who assemble different components whose quantity in accordance with assembly ratio. And finished products are sent to the third stage nodes (i.e., customers). The supply chain system has delivery time constraint and capacity constraint.

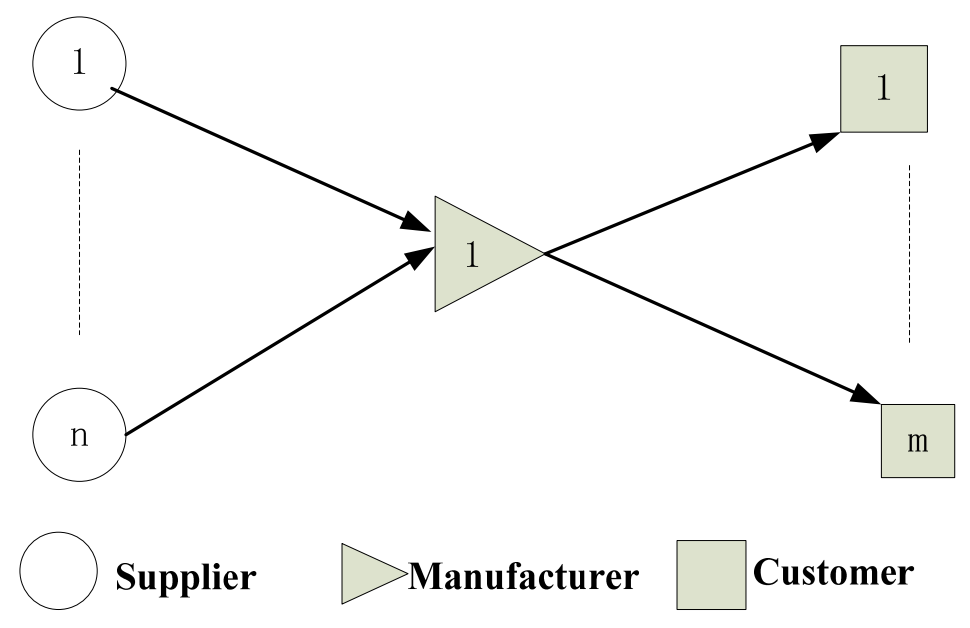

Figure 1. Three-stage supply chain structure diagram of assembly manufacturing 
Planning time $\mathrm{L}$ is from order accept time $\mathrm{T}_{\text {str }}$ to delivery time $\mathrm{T}_{\text {end }}$. Manufacturer must finish and delivery product to customers before $\mathrm{T}_{\text {end. }} \mathrm{L}$ is discrete into $\mathrm{k}$ equivalent intervals that are minimum common divisor of the various types of nodes' cycle length. Constructing $\mathrm{k}$ simultaneous equations for every interval is modeling approach in this paper. It will be in the form of differential non-linear equations

The decision variables are including the processing production lot and component inventory level of each supplier for every interval, and the assembly lot, component inventory level, finished-product inventory level of the manufacturer, and the dispatch volume between different stage nodes every interval. The input parameters are including the boundary of the decision variables, transportation capacity, Storage capacity, Single-trip transportation cost, component and finished product holding unit cost per unit time, production prepare cost per unit time. In the process of supply chain operation, there are non-linear equations reflect the relationship between the variables. Each intermediate node amount of input and output must be equal. And various components in the assembly must meet the ratio constraint and delivery constraint.

The symbol definition is as follows:

$I S_{i}^{k}$ Inventory level of suppliers $i$ in the kth interval, $i=1,2 \ldots . n$.

$P S_{i}^{k}$ Whether suppliers i processing production $i$ in the kth interval which is $0-1$ variable, where $i=1,2 \ldots n$.

IPS $_{i}^{\mathrm{k}}$ Component quantity that suppliers i production $\mathrm{i}$ at the start of the kth interval.

QPS $_{i}^{k}$ Component quantity that suppliersi production $i$ at the end of the kth interval.

$\mathrm{TS}_{\mathrm{i}}^{\mathrm{k}}$ Whether supplier i deliver goods to manufacturers in the kth interval which is $0-1$ variables.

QTS $_{i}^{k}$ Component quantity that supplier i sent to the manufacturers in the kth interval i.e. freight volume.

IMS $_{i}^{\mathrm{k}}$ Inventory level of component $\mathrm{i}$ in the kth interval of manufacturer.

$\mathrm{PM}^{\mathrm{k}}$ Whether manufacturer assemble product in the kth interval, which is $0-1$ variables.

PINS $_{\mathrm{i}}^{\mathrm{k}}$ The ith component quantity that manufacturer assembles in the kth interval.

$\mathrm{MS}_{\mathrm{i}}^{\mathrm{k}_{\mathrm{i}}}$ The ith component quantity accepted by manufacturer in the kth interval after transportation.

$\lambda_{\mathrm{i}}$ The ith component quantity needed of single finished product.

$\mathrm{IF}^{\mathrm{k}}$ Manufacturer's finished product inventory in the kth interval.

IPOUT $^{\mathrm{k}}$ Product's quantity that manufacturers assembled in the kth interval.

$\mathrm{TM}_{\mathrm{j}}^{\mathrm{k}}$ Whether manufacturer sent finished products to the jth customer in the kth interval which is $0-1$ variables, where $\mathrm{j}=1,2 \ldots \mathrm{m}$.

The QTM ${ }_{j}^{\mathrm{k}}$ finished product quantity that manufacturers send to the jth customers in the kth interval.

$\sum_{\mathrm{j}=1}^{\mathrm{m}} \mathrm{TM}_{\mathrm{j}}^{\mathrm{k}}$ The total finished product quantity that manufacturers sent to all customers, where $\mathrm{m}$ is the number of customers.

$\mathrm{TWS}_{\mathrm{j}}$ The start time of the $\mathrm{jth}$ customer can accept product.

$\mathrm{TWE}_{\mathrm{j}}$ The deadline time of the jth customer can accept product.

$I_{j}^{k}$ The jth customer's inventory level in the kth interval..

Mdelay $_{\mathrm{i}}$ Transportation time between manufacturer and the ith supplier.

Mdelay $_{\mathrm{i}}$ Transportation time between manufacturer and the jth customer.

$D_{\mathrm{j}}$ The jth customer order quantity, $\mathrm{j}=1,2 \ldots \mathrm{m}$.

$\mathrm{cp}_{\mathrm{i}}$ Single production preparation cost per unit time of supplier;

$\mathrm{cm}$ Single assembly preparation cost per unit time of manufacturer

$\mathrm{ct}_{\mathrm{i}}$ Transportation cost from the ith supplier to manufacturer.

$\mathrm{ct}_{\mathrm{j}}$ Transportation cost from manufacturer to customer $\mathrm{j}$.

$\mathrm{cis}_{\mathrm{i}}$ Unit component inventory cost per unit time of supplier i .

$\mathrm{cms}_{\mathrm{i}}$ Unit component $\mathrm{i}$ inventory cost per unit time of manufacturer.

cmf Unit finished product inventory cost per unit time of manufacturers.

$\operatorname{cdf}_{\mathrm{j}}$ Unit component inventory cost per unit time of customer $\mathrm{j}$. 
$\mathrm{cps}_{\mathrm{i}}$ Supplier i's maximum production ability.

cpm The manufacturer's maximum assembly capacity.

isca $_{\mathrm{i}}$ The maximum capacity that supplier i can hold .

imsca $_{\mathrm{i}}$ The maximum component i's quantity that manufacturer can hold .

im Finished product's quantity that manufacturer can hold .

$\mathrm{ca}_{\mathrm{i}}$ Capacity of transport car from supplier i to manufacturer.

$\mathrm{ca}_{\mathrm{j}}$ Capacity of transport car from manufacturer to customer $\mathrm{j}$.

delay $y_{\mathrm{i}}$ The time of supplier i's processing single component .

delaym Manufacturer's assembly single production time. period.

So the goal of the system is to minimize the overall three stage supply chain operation cost of the planning

$\min F \cos t$

$$
\begin{aligned}
& F \cos t=\sum_{i=1}^{n} \sum_{k=1}^{T W E} c p_{i} * P S_{i}^{k}+\sum_{k=\max \left(\text { Mdela }_{i}\right)}^{T W E} c m * P M^{k}+\sum_{i=1}^{n} \sum_{k=1}^{T W E} c i s_{i} * I S_{i}^{k}+\sum_{k=\min \left(\text { Mdela }_{i}\right)}^{T W E_{i}} c m s_{i} * I M S_{i}^{k}+\cdots+ \\
& \sum_{k=\min (\text { Mdelay }}^{T W E_{i}} c m f * I F^{k}+\sum_{j=1}^{m} \sum_{k=T W S_{i}}^{T W E_{j}} c d f_{j} * I D_{j}^{k}+\sum_{i=1}^{n} \sum_{k=1}^{T W E} c t_{i} * T S_{i}^{k}+\sum_{j=1}^{m} \sum_{k=1}^{T W E} c t_{j} * T M_{j}^{k}
\end{aligned}
$$

S.t.

$$
\begin{aligned}
& I P S_{i}^{k}=Q P S_{i}^{k+\text { delay }_{i}}, \quad i=1,2 \cdots n \\
& I S_{i}^{k}=I S_{i}^{k-1}+Q P S_{i}^{k}-Q T S_{i}^{k}, \quad i=1,2 \cdots, n \\
& \operatorname{QTS}_{i}^{k}=M S_{i}^{k+\text { Mealy }_{i}}, \quad i=1,2 \cdots, n \\
& I M S_{i}^{k}=I M S_{i}^{k-1}-P I N S_{i}^{k}+M S_{i}^{k}, \quad i=1,2 \cdots, n \\
& \frac{P I N S_{1}^{k}}{P I N S_{i}^{k}}=\frac{\lambda_{1}}{\lambda_{i}}, \quad i=1,2 \cdots, n \\
& \operatorname{PINS}_{1}^{k}=\lambda_{1} \text { POUT }^{k+\text { delaym }} \\
& I F^{k}=I F^{k-1}+P O U T^{k}-\sum_{i=1}^{n} Q T M_{i}^{k} \\
& I D_{j}^{k+\text { Ddelay }_{i}}=Q T M_{j}^{k} \quad j=1,2 \cdots m \\
& Q T M_{j}^{k}=0, \quad k \prec T W S_{i}, \quad j=1,2 \cdots, m \\
& \sum_{k=T W S_{i}}^{T W E_{i}} Q T M_{j}^{k}=D_{j}, \quad j=1,2, \cdots m \\
& I P S_{i}^{k} \leq c p s_{i}, \quad i=1,2 \cdots n \\
& \operatorname{PINS}_{i}^{k} \leq \lambda_{i} \text { cpm }, \quad i=1,2 \cdots n
\end{aligned}
$$




$$
\begin{gathered}
I S_{i}^{k} \leq \text { isca }_{i}, \quad i=1,2 \cdots n \\
I M S_{i}^{k} \leq \text { imsca }_{i}, \quad i=1,2 \cdots n \\
I F^{k} \leq i m f \\
Q T S_{i}^{k} \leq c a_{i}, \quad i=1,2 \cdots n \\
Q T M_{j}^{k} \leq c a_{j}, \quad j=1,2, \cdots m
\end{gathered}
$$

Where Fcost represents objective function, means the supply chain operation cost during whole planning period, including the production preparation costs $\sum_{\mathrm{i}=1}^{\mathrm{n}} \sum_{\mathrm{k}=1}^{\mathrm{TWE}} \mathrm{cp}_{\mathrm{i}} * \mathrm{PS}_{\mathrm{i}}^{\mathrm{k}}$ of supplier and assembly production preparation costs $\sum_{\mathrm{k}=\max (\mathrm{Mdelayi})}^{\mathrm{TWE}} \mathrm{cm} * \mathrm{PM}^{\mathrm{k}}$ of manufacturer, which is not depends on assembly quantity at current interval. Inventory cost including supplier inventory cost $\sum_{\mathrm{i}=1}^{\mathrm{n}} \sum_{\mathrm{k}=1}^{\mathrm{TWE}} \operatorname{cis}_{\mathrm{i}} * \mathrm{I} S_{\mathrm{i}}^{\mathrm{k}}$ and manufacturer's inventory cost including

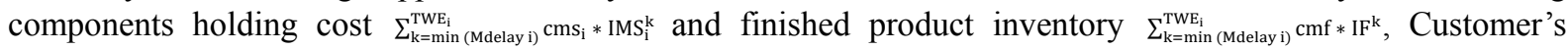
inventory cost $\sum_{\mathrm{j}=1}^{\mathrm{m}} \sum_{\mathrm{k}=\mathrm{TWS}_{\mathrm{j}}}^{\mathrm{TWE}_{\mathrm{j}}} \mathrm{cpf}_{\mathrm{j}} * \mathrm{ID}_{\mathrm{j}}^{\mathrm{k}}$. Transportation cost includes $\sum_{\mathrm{i}=1}^{\mathrm{n}} \sum_{\mathrm{k}=1}^{\mathrm{TWE}} \mathrm{ct}_{\mathrm{i}} * \mathrm{TS}_{\mathrm{i}}^{\mathrm{k}}$ and $\sum_{\mathrm{j}=1}^{\mathrm{m}} \sum_{\mathrm{k}=1}^{\mathrm{TWE}} \mathrm{ct}_{\mathrm{j}} * \mathrm{TM}_{\mathrm{j}}^{\mathrm{k}}$ that present transport cost from supplier to the manufacturer and from manufacturer to the customer respectively. The transportation cost is proportional to the number $\mathrm{N}$ of vehicle used. $\mathrm{N}$ is the rounding integral number of the ratio of traffic amount to car capacity. As it can be seen from the above model, many decision variables are integer and the objective function is nonlinear with variables.

Formula (2)-(18) represent the system different type constraints, and Equations (2) (4) (7) (9) represents the time constraint between each node, including processing time, assembly time, transportation time. Equations (3) (5) (8) are the traffic equilibrium constraint of each node, meaning the sum of node's production quantity and inventory of former interval then subbed by the sending volume to another node equivalent to node's current interval inventory. Equation (6) is the assembly ratio constraint of different components. Equations (10) (11) is the constraints of delivery time and delivery amount. Inequality (12)-(18) is the ability constraint of each node, including maximum value of inventory, maximum production capacity, $y$ transportation equipment maximum capacity. Different types constraints of each time interval are included in model, so compared with other model above model's number of decision variables increased greatly but also more realistic

\section{Solution and Numerical Example}

The optimization model of assembly manufacturing supply chain with delivery constraint belongs to mixed integer nonlinear programming abbreviated as MINLP. There are lots of equality and boundary value constraints in the model. The Sequential Quadratic Programming with super linear convergence rate, abbreviated as SQP and Branch Bound Method are hybrid used to solve the above problems.

Firstly the nonlinear NLIP (nonlinear integer programming) relaxation of the problem NLP (Nonlinear Programming) NLP is solved with SQP. If the solution does not meet the integer constraint, while the solution as a starting point, the original problem is decomposed into two branches, each one each add a new constraint. Thus feasible domain is diminished. Then solving branch of NLP solution and continue to branch sub-problem that does not meet the integer constraint. Branch search will be stopped until the new constraints make the problem of NLP component is gradually turned into an integer. MATLAB programming language and its optimization toolbox are used in this paper to get numerical result

In this section, a supply chain with two suppliers and a manufacturer and two customers is considered. Four group data sets are tested and compared. Assumptions with day being the unit time and zero initial inventories, customer demand are expressed as $\mathrm{D}_{1}(9)=20, \mathrm{D}_{2}(11)=40$, that means delivery the first customer 20 finished product before the ninth day and the second customer 40 finished products before the eleventh day. Different process time cost are presented as delayl $=1$, Mdelayl $=3$, Mdelay $2=2$, delaym $=1$, Ddelayl $=2$, Ddelay2 $=2$. And the assembly ratio of two components is $\lambda_{1} / \lambda_{2}=2 / 3$. In order to study the impact of various cost parameters on optimization results, first set of data as the basic one, then reducing transportation cost in the second group, reducing two suppliers' inventory unit cost per unit time in the third group, reducing the manufacturer's component holding cost per unit time in the fourth group. The parameter change can be seen in table 1 and table 2 . 
Table 1. Transportation cost parameters values in different scenarios

\begin{tabular}{lllll}
\hline $\boldsymbol{N O}$. & $c t_{1}$ & $c t_{2}$ & $c t_{3}$ & $c t_{4}$ \\
\hline Scenario 1 & 50 & 40 & 50 & 40 \\
Scenario 2 & 10 & 8 & 18 & 8 \\
\hline
\end{tabular}

Table 2. Unit inventory holding cost per unit time of manufacturer and suppliers values in different scenario

\begin{tabular}{llllll}
\hline \multirow{2}{*}{ NO. } & Supplies & \multicolumn{5}{c}{ Manufacturer } \\
\cline { 2 - 6 } & cis & $c i s_{2}$ & $c m s_{1}$ & $c m s_{2}$ & 10 \\
\hline Scenario 1 & 20 & 10 & 9 & 8 & 10 \\
Scenario 3 & 2 & 1 & 9 & 8 & 5 \\
Scenario 4 & 20 & 10 & 4 & 3 & 5 \\
\hline
\end{tabular}

According to the above optimization model and solution algorithm, then results can be calculated and shown in Table 3 .

Table 3. Optimization results corresponding to different scenarios

\begin{tabular}{lcccc}
\hline NO. & Scenario 1 & Scenario 2 & Scenario 3 & Scenario 4 \\
\hline NV The total number of used vehicles & 6 & 7 & 6 & 6 \\
IS The total inventory quantity of two & 110 & 60 & 140 & 70 \\
supplier & & 40 & 20 & 1520 \\
IM The total inventory quantity of & 50 & 1802 & 1350 & \\
manufacturer \\
$\begin{array}{l}\text { F The sum of supply chain costs (i.e. the } \\
\text { objective function value) }\end{array}$
\end{tabular}

\section{Discussion and Conclusion}

From the numerical example it can be conclude that:

(1) When reducing transportation cost, the number of used vehicles will increase. But number change in our example, because the transport cost is much higher than other cost. And even after reduced, it would be still greater than the other and a majority of the proportion of total cost. That's why the fluctuation of the total number of transportation times is small.

(2) When reducing the two suppliers' unit component holding cost per unit time substantially. The total cost of supply chain operation will decreased mostly, up to $49.06 \%$. And it will decrease up to $27.2 \%$ of supplier's inventory.

(3) If reducing the manufacture's component holding cost per unit time, the component inventor level of manufacturer will significantly increase. Meanwhile, compared with the third data set, the inventory level of the supplier will reduce that it is corresponded to the reality.

Above optimization method can be used to solve the multi-periods lot optimization problem of the assembly manufacturing supply chain. Furthermore, this model can also analyze the mutual relationship between input parameters, it is very helpful to improve and complete the existing structure of supply chain.

\section{Acknowledgements}

This work was financially supported by the talented person Foundation of Central South Forestry University of Science and Technology, Hunan Province Colleges and universities Scientific Research Projects (No. 12C0435). And the work was financially supported by the Central South University 985 Project Resource-conserving and 
Environment-friendly Society (No. ZNLX1113), National Social Science Foundation of China (No.11CGL032), Hunan Province Science and Technology Development Funds (No.2010FJ3007) and Freedom Explore Program of Central South University (NO.201012200100).

\section{References}

Aggarwal, A., \& Park, J. K. (1993). Improved algorithms for economic lot size problems. Operations Research, 41(3), 549-571. http://dx.doi.org/10.1287/opre.41.3.549

Anily, S., Tzur, M., \& Wolsey, L. A. (2009). Multi-item lot-sizing with joint set-up costs. Mathematical programming, 119(1), 79-94. http://dx.doi.org/10.1007/s10107-007-0202-9

Dan, B., Xiao, J., Liu, X. H., Zhang, X. M., Li, Z. W., \& Tang, H. L. (2007). Batch scheduling of a multi-stage supply chain with due windows. Computer Integrated Manufacturing Systems Beijing, 13(2), 1006-5911.

Federgruen, A., \& Tzur, M. (1991). A simple forward algorithm to solve general dynamic lot sizing models with $\mathrm{n}$ periods in $0 \quad(\mathrm{n} \log \mathrm{n})$ or $0 \quad(\mathrm{n})$ time. Management Science, 37(8), 909-925. http://dx.doi.org/10.1287/mnsc.37.8.909

Glock, C. H. (2012). The joint economic lot size problem: A review. International Journal of Production Economics, 135(2), 671-686. http://dx.doi.org/10.1016/j.ijpe.2011.10.026

Hwang, H. C., Jaruphongsa, W., Çetinkaya, S., \& Lee, C. Y. (2010). Capacitated dynamic lot-sizing problem with delivery/production time windows. Operations Research Letters, 38(5), 408-413. http://dx.doi.org/10.1016/j.orl.2010.04.009

Jaruphongsa, W., \& Lee, C. Y. (2008). Dynamic lot-sizing problem with demand time windows and container-based transportation cost. Optimization Letters, 2(1), 39-51. http://dx.doi.org/10.1007/s11590-006-0042-1

Kim, T., \& Glock, C. H. (2013). A multi-stage joint economic lot size model with lead time penalty costs. Computers \& Industrial Engineering, 66(1), 133-146. http://dx.doi.org/10.1016/j.cie.2013.05.019

Lee, C. Y., Çetinkaya, S., \& Wagelmans, A. P. M. (2001). A dynamic lot-sizing model with demand time windows. Management Science, 47(10), 1384-1395.

Osman, H., \& Demirli, K. (2012). Economic lot and delivery scheduling problem for multi-stage supply chains. International Journal of Production Economics, 136(2), 275-286. http://dx.doi.org/10.1016/j.ijpe.2011.12.001

Song, J. S., \& Zipkin, P. (2003). Supply chain operations: Assemble-to-order systems. Handbooks in operations research and management science, 11, 561-596. http://dx.doi.org/10.1016/S0927-0507(03)11011-0

Van Hoesel, C. P. M., \& Wagelmans, A. P. M. (1996). An O (T3) algorithm for the economic lot-sizing problem with constant capacities. Management Science, 42(1), 142-150. http://dx.doi.org/10.1287/mnsc.42.1.142

Wu, T., Shi, L., Geunes, J., \& Akartunalı, K. (2011). An optimization framework for solving capacitated multi-level lot-sizing problems with backlogging. European Journal of Operational Research, 214(2), 428-441. http://dx.doi.org/10.1016/j.ejor.2011.04.029

\section{Copyrights}

Copyright for this article is retained by the author(s), with first publication rights granted to the journal.

This is an open-access article distributed under the terms and conditions of the Creative Commons Attribution license (http://creativecommons.org/licenses/by/3.0/). 